\title{
Pré-natal da gestante de risco habitual: potencialidades e fragilidades
}

Prenatal care of habitual- risk pregnant women: potentialities and weaknesses

Prenatal de la gestante de riesgo habitual: potencialidades y fragilidades

\section{Andressa Arraes Silva', Mara Julyete Arraes Jardim ${ }^{\mathrm{II}}$, Claudia Teresa Frias Rios ${ }^{\mathrm{II}}$ Lena Maria Barros Fonseca ${ }^{\mathrm{IV}}$, Liberata Campos Coimbra ${ }^{\mathrm{v}}$}

\begin{abstract}
Resumo: Objetivo: conhecer as potencialidades e fragilidades na consulta pré-natal de risco habitual. Método: estudo qualitativo, desenvolvido com vinte gestantes que realizaram o pré-natal na Atenção Primária à Saúde do município de São Luís, no ano de 2017. Para análise dos dados utilizou-se a Análise Temática com base nos parâmetros preconizados pelo Ministério da Saúde. Resultados: o acolhimento, o fácil acesso, a realização de exames e os grupos de gestantes configuram-se como potencialidades do pré-natal. A falta de organização das unidades, de medicamentos de uso essencial, de recursos materiais, o tempo prolongado para início das consultas e para as realizações dos exames consistiram em fragilidades. Conclusões: a avaliação da assistência pré-natal a partir da percepção das usuárias trouxe contribuições para intervenções nas fragilidades dos serviços de saúde às gestantes, e o atendimento de acordo com o que está preconizado pelo Ministério da Saúde.
\end{abstract}

Descritores: Cuidado pré-natal; Humanização da assistência; Enfermagem no consultório

Abstract: Objective: to know the potentialities and weaknesses in the prenatal consultation of habitual risk. Methods: qualitative study, developed with twenty pregnant women who underwent prenatal care at Primary Health Care in the city of São Luís in 2017. Data analysis used the Thematic Analysis based on the parameters recommended by the Ministry of Health. Results: the reception, the easy access, the examinations and the groups of pregnant women are configured as prenatal potentialities. The lack of organization of the units, of essential drugs, of material resources, the long time to start consultations and the accomplishment of the examinations constituted weaknesses. Conclusions: the assessment of prenatal care from the users' perceptions brought contributions to interventions in the weaknesses of health services to pregnant women, according to the recommendations of the Ministry of Health.

\footnotetext{
${ }^{\text {I }}$ Enfermeira. Mestre em Enfermagem. Universidade Estadual do Maranhão. Bacabal-MA, Brasil. E-mail: andressinha_arraes5@hotmail.com. ORCID: https://orcid.org/0000-0002-1699-5597

II Enfermeira. Mestre em Enfermagem. Universidade Estadual do Maranhão. Coroatá-MA, Brasil. E-mail: mara_arraes@hotmail.com. ORCID: https://orcid.org/0000-0002-2428-9123

${ }^{\text {III }}$ Enfermeira. Doutora em Saúde Coletiva. Universidade Federal do Maranhão. São Luís-MA, Brasil. E-mail: ctfrios@hotmail.com. ORCID: https://orcid.org/0000-0003-4988-0099

IV Enfermeira. Doutora em Biotecnologia. Universidade Federal do Maranhão. São Luís-MA, Brasil. E-mail: lenabarrosf@gmail.com. ORCID: https://orcid.org/0000-0002-6499-1005

v Enfermeira. Doutora em Políticas Públicas. Universidade Federal do Maranhão. São Luís-MA, Brasil. E-mail: liberatacoimbra@gmail.com. ORCID: https://orcid.org/0000-0002-3661-638X
} 
Descriptors: Prenatal care; Humanization of assistance; Office nursing

Resumen: Objetivo: conocer las potencialidades y fragilidades en la consulta prenatal de riesgo habitual. Métodos: estudio cualitativo, desarrollado con veinte gestantes, que realizaron el prenatal en la Atención Primaria a la Salud, del municipio de São Luís, en el año 2017. Para análisis de los datos, se utilizó el Análisis Temático, con base en los parámetros determinados por el Ministerio de Salud. Resultados: la acogida, el fácil acceso, la realización de exámenes y los grupos de gestantes se configuran como potencialidades del prenatal. La falta de organización de las unidades, de medicamentos de uso básico, de recursos materiales, el tiempo prolongado para el inicio de las consultas y para la realización de los exámenes consistieron en fragilidades. Conclusión: la evaluación de la asistencia prenatal, a partir de la percepción de las usuarias, aportó contribuciones para intervenciones en las fragilidades de los servicios de salud a las gestantes y para garantizar la atención de acuerdo con lo que está determinado por el Ministerio de Salud.

Descriptores: Atención prenatal; Humanización de la atención; Enfermería de consulta

\section{Introdução}

O acompanhamento pré-natal de risco habitual é caracterizado pelo atendimento à gestante que não apresenta fatores de risco individual, sociodemográfico e relacionados à história obstétrica anterior, doença ou agravo que possam interferir negativamente na evolução da gravidez. Pode ser realizado tanto por médicos quanto por enfermeiros, na rede de Atenção Primária à Saúde (APS), as quais são consideradas portas de entradas das gestantes aos serviços de pré-natal. A Estratégia Saúde da Família (ESF) é caracterizada como um modelo assistencial voltado para o desenvolvimento de ações individuais e coletivas, de acompanhamento e promoção do atendimento pré-natal humanizado. O Enfermeiro, profissional integrante da equipe da ESF, deve ser capaz de identificar situações de risco e agravos à saúde da gestante que interferem na qualidade da consulta pré-natal. ${ }^{1}$

Apesar da qualidade da assistência pré-natal estar diretamente associada ao menor grau de morbimortalidade materno-infantil, ainda permanece a preocupação mundial, principalmente nos países em desenvolvimento, nos índices de morte materna e neonatal em decorrência da gravidez e do parto, demonstrando fragilidade na assistência pré-natal. ${ }^{2}$

O desenvolvimento do pré-natal na APS pode resultar em potencialidades ou fragilidades na assistência, temas atualmente discutidos no âmbito da Estratégia da Saúde da 
Família, com vistas ao ordenamento do trabalho dos profissionais, de modo especial na área da Saúde da Mulher. Entende-se por potencialidades o que é relativo ao vigor e importância, e as mesmas podem ser vistas como um fator determinante para uma assistência ofertada de forma sistematizada, articulada e resolutiva, garantindo os princípios de integralidade e humanização. Já as fragilidades referentes à consulta pré-natal podem ser entendidas como um cuidado pouco resolutivo, devido à adoção de práticas fragmentadas no cuidado à gestante, além de recursos humanos insuficientes, falhas na comunicação e recursos materiais indisponíveis, resultando em deficiência na qualidade do cuidado. ${ }^{3}$

É consensual que o Brasil nos últimos 20 anos tem apresentado importantes avanços na redução da mortalidade materna com a elaboração de políticas e programas destinados à saúde da mulher, que se intensificaram a partir da instituição do Programa de Humanização do Pré-Natal e Nascimento (PHPN) no ano de 2000, pelo Ministério da Saúde (MS). O objetivo era reduzir as altas taxas de morbimortalidade materna e perinatal, ampliando o acesso ao pré-natal, estabelecendo critérios para qualificar as consultas (número mínimo de seis consultas na gestação e uma no puerpério), além de promover pacote mínimo de exames laboratoriais, atividades educativas, classificação de risco e vínculos institucionais. ${ }^{4}$ No que concerne à atenção pré-natal, esta deve ser de fácil acesso e realizada mediante condutas acolhedoras que integrem ações de promoção, prevenção e assistência à saúde da gestante e do bebê em todos os níveis de atenção. A capacitação dos profissionais envolvidos nessa assistência também é fundamental para o alcance da qualidade do cuidado. ${ }^{5}$

Os esforços com o desenvolvimento do PHPN não foram suficientes para produzirem efeitos resolutivos. Foi então instituída pelo MS a Rede Cegonha (RC), com o propósito de assegurar à mulher o direito ao planejamento reprodutivo e à atenção humanizada à gravidez, ao parto e ao puerpério, bem como à criança o direito ao nascimento seguro e ao crescimento e 
desenvolvimento saudáveis. Tem como princípio organizar a Rede de Atenção a Saúde Materna e Infantil, garantindo acesso, acolhimento e redução da mortalidade materna e infantil. ${ }^{6}$

Essas preocupações estão baseadas no conhecimento acerca das taxas de mortalidade materna e neonatal no Brasil e na certeza de que as fragilidades são reflexos da qualidade da assistência prestada às gestantes durante o pré-natal, parto e nascimento. Caso os serviços de saúde ampliassem os direitos sexuais e reprodutivos à mulher e garantissem uma atenção obstétrica segura e respeitosa, $95 \%$ dos óbitos maternos no mundo poderiam ser evitados. ${ }^{7}$ Acredita-se que para melhorar a qualidade da assistência pré-natal é necessário reorganizar o processo de trabalho visando garantir a ampliação do acesso, além de capacitar os recursos humanos, proporcionando acolhimento e apoio integral às gestantes e suas famílias. Esse apoio deve partir de ações educativas com o objetivo de aumentar o nível de orientações das gestantes a respeito dos direitos, riscos e complicações na gravidez e no parto, incentivando seu empoderamento. ${ }^{8}$

Portanto, a pesquisa justifica-se pela importância da opinião das gestantes a respeito da consulta e demais aspectos da assistência pré-natal, bem como dos cuidados percebidos por elas como indicador na avaliação da qualidade do pré-natal na Atenção Primária à Saúde. Para consecução desse estudo, buscou-se responder ao seguinte questionamento: Que potencialidades e fragilidades, nas experiências das gestantes, são encontradas na consulta de pré-natal de risco habitual que interferem na qualidade na Atenção Primária à Saúde?

O estudo teve como objetivo conhecer as potencialidades e fragilidades na consulta pré-natal de risco habitual, nas experiências das gestantes.

\section{Método}

Trata-se de uma pesquisa descritiva, de abordagem qualitativa, realizada com 20 gestantes atendidas na APS de um distrito sanitário da cidade de São Luís, Maranhão. A coleta 
de dados foi realizada no período de julho a setembro de 2017, por meio de entrevista semiestruturada, cujo instrumento foi elaborado e testado previamente, contendo questões objetivas referentes aos dados sociodemográfico, econômico e obstétrico e questões referentes a opiniões das gestantes sobre as consultas de pré-natal. Os modelos de serviços incluídos neste estudo foram: Unidade Mista, Centro de Saúde e Estratégia Saúde da Família.

As participantes foram abordadas nos serviços de saúde durante a consulta de prénatal, por intermédio dos profissionais dos serviços. Os critérios de inclusão foram: gestantes de risco habitual (incluindo menores de 18 anos e maiores de 35 anos, por ter grande número de mulheres nessa faixa etária utilizando dos serviços de pré-natal na APS); a partir da 30 semana de gravidez que tivessem realizado, no mínimo, três consultas de pré-natal (acredita-se que seja um número suficiente para que elas consigam realizar uma análise da assistência recebida); gestantes sem histórico de transtorno mental e que estivessem portando caderneta da gestante.

Todas as entrevistadas foram informadas sobre os objetivos e demais aspectos da pesquisa e solicitado, após os esclarecimentos, a assinatura do Termo de Consentimento Livre e Esclarecido ou do Termo de Assentimento, para menores de 18 anos, juntamente com a autorização do responsável, assegurando uma participação voluntária e mantendo a privacidade quanto aos dados fornecidos. Para garantir o anonimato, as gestantes foram identificadas pela abreviatura da palavra gestante seguida de um número correspondente à ordem em que cada gestante foi entrevistada (GESTA.01).

Os dados foram interpretados utilizando-se a Análise Temática ${ }^{9}$ e analisados com base nos parâmetros de adequação da assistência pré-natal preconizados pelo MS.1,4-6,10-11 A pesquisa obedeceu às normas referidas pela Resolução 466/2012 do Conselho Nacional de Saúde $^{12}$, cuja coleta de dados só ocorreu após aprovação do Comitê de Ética em Pesquisa da Universidade Federal do Maranhão (UFMA) sob o parecer número 1.999.550, em 04 de Abril de 2017. 


\section{Resultados e discussões}

\section{Aspectos sociodemográficos e obstétricos das gestantes}

A partir da análise das características sociodemográficas das 20 gestantes entrevistadas destacou-se que a maioria estava na faixa etária de 26 a 35 anos. É válido ressaltar que duas dessas mulheres estavam na faixa etária menor que 18 anos. Quanto ao estado civil, 10 relataram viver em uma união estável, 5 casadas e 5 solteiras. A ausência de um parceiro ou acompanhantes nas consultas de pré-natal, pode levar à um maior risco para adoecimento, estresse psicológico elevado e ansiedade relacionada à maternidade, ocasionando maior possibilidade de desenvolverem partos prematuros. ${ }^{10}$

Em relação à raça 16 gestantes se declararam pardas. Segundo o MS as gestantes pardo-negras estão mais propensas a adquirir hipertensão arterial e diabetes devido à sua predisposição biológica. ${ }^{1}$ Em se tratando da renda familiar, a maioria disse sobreviver com um a dois salários mínimos e apenas uma diz não ter renda fixa. É imprescindível que os profissionais de saúde estejam atentos às condições socioeconômicas de seus usuários e aos possíveis riscos de saúde advindos da baixa renda familiar, como o baixo peso do recém-nascido, partos prematuros, dentre outras complicações durante o período gravídico. ${ }^{13}$ Quando questionadas a respeito de sua escolaridade, a maioria relatou ter terminado o ensino médio e uma concluiu o ensino superior. O baixo grau de escolaridade associado ao baixo nível socioeconômico favorece o início tardio do pré-natal, o elevado nível de absenteísmo e a adoção de hábitos inadequados durante o período gestacional. ${ }^{14}$

A análise dos dados obstétricos das gestantes apontou que 16 estavam na sua primeira gestação, cinco estavam na segunda gestação, duas estavam na terceira e duas encontravam-se na quarta gestação. Dos partos já vivenciados pelas gestantes deste estudo, a 12 foram de forma natural e 3 foram partos cesarianos. Segundo o MS um dos critérios para a efetividade da assistência pré-natal está relacionado com o incentivo ao parto normal e à 
redução da cesárea desnecessária. ${ }^{1}$ Em se tratando da escolha do tipo de parto, o enfermeiro é responsável por disseminar, durante o pré-natal, os benefícios e as vantagens relacionadas ao parto normal, o qual faz parte de um processo fisiológico com baixos índices de infecção quando comparados a um parto cesáreo. ${ }^{2}$

Quando questionado às multigestas se elas haviam realizado o pré-natal na gestação anterior, todas responderam de forma positiva. Dentre elas, a maioria realizou as consultas do pré-natal intercaladas entre enfermeiro e médico, como recomenda o Ministério da Saúde. ${ }^{1}$ A partir da análise das mensagens emitidas pelas gestantes deste estudo, tomando como base os parâmetros de adequação da assistência pré-natal preconizados pelo MS, foi possível abstrair duas categorias temáticas: potencialidades que qualificam a consulta pré-natal e fragilidades encontradas pelas gestações na consulta pré-natal.

\section{Potencialidades que qualificam a consulta pré-natal}

O Programa de Humanização no Pré-natal e Nascimento estabelece que toda gestante assistida pelo Sistema Único de Saúde tem direito ao acesso e atendimento dignos e de qualidade durante a sua gestação, parto e puerpério. Essa assistência deve ser realizada de forma humanizada, organizada e segura. É obrigação de toda unidade de saúde receber com dignidade a gestante, por meio de condutas acolhedoras. ${ }^{4}$

Uma assistência pré-natal de qualidade necessita ser construída por meio de práticas articuladas que envolvam a dimensão subjetiva, social, econômica e cultural das gestantes e seus familiares. É de fundamental importância que a equipe multidisciplinar desenvolva o cuidado à gestante desde a descoberta da gravidez até o período puerperal, de forma integral. Essa articulação de saberes multidisciplinar tende a despertar novos olhares para as práticas de acompanhamento pré-natal, o que potencializa a assistência. ${ }^{15}$ Tomando como base as potencialidades do pré-natal, nesta categoria foi possível conhecer as percepções das gestantes a 
respeito da consulta desenvolvida na APS. Percebeu-se que o bom atendimento dos profissionais configura-se como potencialidade para o relacionamento interpessoal, como pode ser visto nas seguintes falas:

toda minha consulta eu sou bem recebida, nunca fui ignorada, nunca fui maltratada, nem pelos funcionários, nem pelas médicas, nem pelos enfermeiros. (GESTA.15)

a forma como eu estou sendo tratada pelas enfermeiras, elas me ajudam quando eu estou sentindo dor. $O$ atendimento dos profissionais da recepção, eles são bem educados, isso para mim é um aspecto muito bom.(GESTA.06)

a enfermeira me atendeu muito bem e relatou meus exames muito bem também. (GESTA.03)

as enfermeiras são muito atenciosas, perguntam, tiraram as dúvidas, deram número do whatsApp para gente conversar se acontecesse alguma coisa, receitaram os remédios. Eu não tenho nada o que reclamar. (GESTA.20)

um ponto positivo desse lugar é o atendimento de todos que é ótimo, eu gostei bastante, as enfermeiras sabem conversar, a gente se sente bastante acolhido. (GESTA.14)

Os depoimentos demonstram que as gestantes estão satisfeitas com o acolhimento que está sendo proporcionado pelo profissional de saúde nas consultas de pré-natal, caracterizando uma potencialidade. De acordo com o MS, o acolhimento consiste em uma diretriz da Política Nacional de Humanização e deve fazer parte de toda assistência à saúde da gestante. Implica na escuta ativa das usuárias, na postura ética profissional, reconhecimento do protagonismo da mulher, na resolução dos problemas e compartilhamento dos saberes. ${ }^{4}$

Foi feito um estudo ${ }^{16}$ de Coorte prospectivo dos nascidos vivos com idade gestacional de 23 a 31 semanas, peso ao nascer de 500 a 1.499g, sem malformações, realizado em 19 
maternidades públicas de nove capitais na Região Nordeste do Brasil, no período de julho a dezembro de 2007. Os autores destacam que a qualidade do pré-natal, de acordo com as gestantes, está associada à assistência integral do enfermeiro. Esta assistência deve ser prestada de forma humanizada por meio da escuta, do olhar, do toque e da conversa sobre a saúde da gestante e do seu bebê, fornecendo informações necessárias para que ela se sinta segura e tire todas as suas dúvidas.

A adesão das gestantes aos serviços de saúde que oferecem a consulta de pré-natal é influenciada, principalmente, pela empatia que elas sentem pelos profissionais e pela Unidade de Saúde. O cuidado humanizado e o acolhimento estão diretamente relacionados à construção de vínculos, possibilitando o acompanhamento adequado da gestação. Os profissionais envolvidos nesse cuidado devem estar preparados para garantir a integralidade da assistência, amparados pelo bom relacionamento interpessoal. ${ }^{17}$ Algumas das gestantes relataram ter escolhido aquela determinada serviço de saúde para realizarem seu pré-natal devido à facilidade na marcação das consultas e ao fácil acesso. Esses dados foram caracterizados como potencialidades encontradas na assistência pré-natal, de acordo com as seguintes falas:

o atendimento é rápido, a gente marca e sempre dá certo, os médicos não faltam. (GESTA.17)

aqui é mais perto da minha casa, é mais fácil da gente marcar a consulta, e a gente é bem atendida. (GESTA.18)

aqui é perto de casa, a enfermeira é uma pessoa muito gentil, compreensiva, fala com a gente bacana. Quando a gente chega na recepção, eles dão prioridade para gente também. (GESTA.09)

esse negócio novo do exame, da rede cegonha, que a gente faz sem pagar ficou ótimo. (GESTA.05)

tem muitas pessoas que tem dificuldade com problema de receber o resultado do exame, de marcar, eu não tive esse problema. Todos os 
exames que eu fiz eu consegui marcar e receber no dia, nunca deixei de fazer nenhuma. Todas as minhas consultas eu fui bem recebida. (GESTA.08)

a questão de fazer os exames laboratoriais de graça é maravilhosa. (GESTA.04)

O fácil acesso aos serviços de saúde relatado pelas gestantes, é um determinante potencializador para a adesão ao pré-natal. Esses depoimentos estão em consonância ao que é preconizado com o MS, que diz que toda gestante deve ser atendida em sua área de abrangência. As equipes de saúde são responsáveis por assegurar a continuidade do atendimento pré-natal de todas as gestantes, da área de abrangência da unidade de saúde, que realizam o pré-natal. ${ }^{1}$

A fala da GESTA.05 evidencia a importância da RC como uma das estratégias que favorece a qualificação da assistência pré-natal. De acordo com a Portaria $n^{\circ} 1.459 / 2011$, a RC em seu componente I, compreende uma das ações de atenção à saúde no pré-natal: a realização dos exames solicitados pelos profissionais no momento da consulta e acesso aos resultados em tempo oportuno que devem ser garantidas pelas Unidades de Saúde. ${ }^{6}$

As gestantes deste estudo que usufruíram das atividades nos grupos de gestantes, consideraram fundamental sua integração no grupo durante a assistência pré-natal. Elas afirmaram que as discussões de assuntos variados pelos profissionais da equipe multiprofissional foram enriquecedoras, suprindo a lacuna deixada durante a consulta como, por exemplo, os direitos das gestantes, maternidade de referência para o parto, acompanhamento odontológico e amamentação, as quais foram destacadas como potencialidades nas falas abaixo:

eu acho o grupo importante, a gente troca conhecimento e tira dúvidas, fica sabendo de muita coisa que a gente não sabia. Elas aconselharam a gente a ler a caderneta da gestante, que fala muita coisa sobre nossos direitos. (GESTA.14) 
aqui é bom porque têm as palestras que eles te orientam bastante, eu não sabia que tinha, a enfermeira me indicou e assim que eu comecei a vir nas palestras, eu gostei muito e aprendi muito também. É uma orientação a mais, tu não chegas de paraquedas para ser mãe, essa orientação tu vais levar para cuidar do teu filho e de si mesmo. (GESTA.12)

nas palestras, eu aprendi muita coisa porque teve a dentista, teve a fonoaudióloga, teve as enfermeiras. Hoje que eu participei foi sobre amamentação, gostei e incentivo as outras gestantes a participarem também. (GESTA.20)

sobre a reunião das gestantes, mudou muita coisa na minha vida, porque eu tinha muita dúvida sobre a minha gestação, aqui tiraram bastante dúvida. (GESTA.18)

no grupo que eu participei da palestra, eles davam orientação em relação a tudo, entendeu? Desde o começo da gestação até o momento do parto e lá eles explicavam muito bem, eu gostei demais. (GESTA.06)

aqui tem reunião com as gestantes que é um momento muito bom em que todas as gestantes aprendem juntas. Tem visita na maternidade que nós iremos ganhar o bebê. (GESTA.16)

o grupo é muito bom porque a gente aprende sobre o cuidado com o bebê logo nos primeiros dias de vida, não dar chupeta, não dar mamadeira, a importância da amamentação e sobre o bico do peito para não passar sabão, passar só o leite do peito mesmo pra hidratar. (GESTA.13)

Percebe-se nos depoimentos que a participação das mulheres em grupos de gestantes possibilita a aproximação e o fortalecimento do vínculo com a Unidade de Saúde e permite que o profissional desenvolva o seu papel de educador. Esses encontros de gestantes têm como objetivo orientar suas ações, levantar discussões e sanar as dúvidas durante o período gestacional, a fim de contemplar suas necessidades. Além de ser um momento de troca de experiência, o grupo de gestantes permite que essas mulheres sejam multiplicadoras de 
conhecimentos. ${ }^{18}$ Ressalta-se a importância dada pelas gestantes ao uso orientado da Caderneta da Gestante como instrumento facilitador e potencializador para o bom acompanhamento prénatal por conter temas fundamentais, como os direitos de toda mulher grávida, tais como: trabalhistas, sociais, estudantis, prioridade nos serviços de saúde, ser informada e de visitar antes do parto a maternidade de referência, ter acompanhante durante o trabalho de parto, parto e pós-parto, no SUS. ${ }^{11}$

Nesta categoria, foi possível inferir que as potencialidades da consulta pré-natal apontadas pelas gestantes, se referiram ao fácil acesso aos serviços de saúde e à boa interação com o profissional. A qualidade da consulta pré-natal baseou-se no cuidado realizado pelos profissionais de saúde, sendo a enfermeira uma das profissionais responsáveis pela melhoria da assistência à mulher.

\section{Fragilidades encontradas pelas gestantes na consulta pré-natal}

Nesta categoria evidenciaram-se diversos aspectos que podem ser consideradas como fragilidades na assistência pré-natal. Boa parte das gestantes destacou a falta de organização dos serviços de saúde para a assistência pré-natal, tais como a falta de consultório de enfermagem para atender as gestantes e o tempo prolongado de espera para início das consultas a falta de garantia e dificuldade para a realização dos exames complementares; estrutura física insatisfatória e a falta de medicamentos essenciais de uso na gravidez, como podem ser vistos:

o ruim é porque eles não são organizados. Na hora que eu estava na fila eles fizeram uma bagunça porque a sala que tinha lá era só gestante mais estava para várias outras consultas. A pessoa chega aqui 6 horas, 5 horas da manhã e outra pessoa que chega aqui 9 horas eles colocam na frente, marcam uma consulta pra 7 horas e começa a atender 8 ou 9 horas. (GESTA.02) 
para ser sincera aqui o pré-natal está mais ou menos, por questões de falta de materiais pra realizar a consulta completa como, por exemplo, não tem a fita métrica para medir a barriga. (GESTA.08)

em relação ao lugar, não está bom, por causa da estrutura, nem sempre o ventilador está prestando, ai nem sempre tem cadeira para sentar, porque às vezes está muito cheio. Em relação à marcação de consulta também, porque demora muito. (GESTA.07)

a gente precisa fazer um preventivo ai não tem, e quando tem, demora uns dois meses pra chegar; precisa de um teste rápido, não tem. Sempre falta alguma coisa, um bebedor, não tem papel higiênico no banheiro, não tem água na descarga. A médica me passou sulfato ferroso e ácido fólico, ai tem que comprar, sendo que tem uma farmácia dentro do consultório só que nunca tem os medicamentos desde o começo da minha gravidez.(GESTA.16)

o pré-natal não está sendo melhor porque falta mais orientação em relação ao meu parto. (GESTA. 19)

Os depoimentos demonstram insatisfação das gestantes pela falta de atendimento a seus direitos de cidadania, tanto pela gestão como pelos profissionais de saúde, o que pode refletir na falta de pontualidade e assiduidade da gestante na consulta de pré-natal. Esses achados estão contrariando o que é determinado pelo o MS, em que todos os Estados e municípios devem dispor de uma rede de serviços organizada para o desenvolvimento dessa assistência, sendo considerados os seguintes critérios: as unidades que prestam atenção prénatal devem estar vinculadas às maternidades/hospitais, de acordo com a definição do gestor local; devem ser garantidos recursos humanos, físicos, materiais e técnicos necessários para a assistência pré-natal, parto e pós-parto, sendo estabelecidos os critérios mínimos para o funcionamento da APS e maternidades; garantir atendimento a todas as gestantes que buscam os serviços de saúde; garantir a realização dos exames complementares para a avaliação do estado de saúde das gestantes e de seu concepto. ${ }^{5}$ 
De acordo com as falas das gestantes, considerou-se como fragilidade a falta ou deficiência de um equipamento essencial para o acompanhamento pré-natal, o Sonar Doppler, que visa acompanhar a vitalidade fetal. Apesar de todas as gestantes relatarem que o momento mais esperado e desejado por elas é a hora da ausculta dos batimentos cardíacos do seu bebê, na maioria das vezes, elas ficaram desapontadas por não haver aparelho suficiente ou em perfeito funcionamento, o que as impediam de ouvir os batimentos cardiofetais:

um ponto bastante negativo é aquele aparelhinho para escutar o coração da criança, que fica mudando de uma sala para outra todo tempo. (GESTA.14)

o ponto negativo é que aqui é rápida a consulta nunca me examinaram, a única parte que eles examinam é pra saber o coração do bebe e ainda não dar de ouvir porque a máquina não funciona. (GESTA.17)

aquele aparelhinho para escutar o coração da criança não tem em todo consultório. Eu acho que deveria ter um em cada consultório, seria o certo. (GESTA.09)

o ultrassom é um ponto negativo, porque eles pedem hoje, ai daqui um mês a gente consegue agendar pelo SUS, ai não consegue fazer na data certa, tem que desembolsar o dinheiro para fazer e eu acho que o governo poderia estar cobrindo isso. (GESTA.04)

A falta ou deficiência da avaliação da vitalidade fetal, assim como do exame físico obstétrico, são aspectos de extrema importância no acompanhamento da gestante. Essa realidade não é pontual apenas ao local do estudo, mas é uma tendência do sistema de saúde como um todo. Os achados expostos igualam-se ao que foi encontrado em outra pesquisa realizada no Município de Rondonópolis, ${ }^{17}$ onde foi observada carência de materiais nas UBS para realização do atendimento pré-natal como, por exemplo, Sonar Doppler ou estetoscópio de Pinard que servem para a verificação dos batimentos cardiofetais. As unidades também possuíam um único aparelho e este era dividido para todas as equipes. 
15 I Silva AA, Jardim MJA, Claudia Rios TF, Fonseca LMB, Coimbra LC

Outra fragilidade demonstrada nas falas foi o acesso à ultrassonografia obstétrica pelo SUS, uma vez que foi relatada dificuldade para agendamento do exame e a longa espera para entrega dos resultados. Esse fato impossibilitava a gestante de fazer o exame e ter o resultado em tempo hábil para avaliação na próxima consulta pré-natal. A ultrassonografia obstétrica, assim como os exames laboratoriais, faz parte da rotina pré-natal preconizada pelo MS.

Esses dados são compatíveis com o que foi encontrado nas Unidades Básicas de Saúde da Família do município de Fortaleza, onde foi detectada insatisfação quanto à realização da ultrassonografia obstétrica, pelo fato de ser preciso ir a clínicas particulares para recebimento de resultado imediato, gerando incômodo para as gestantes que utilizam dos serviços públicos de saúde, interferindo assim na qualidade da assistência pré-natal. Problemas como esse não dependem do bom desempenho profissional, mas da articulação entre administradores e gestores de saúde, de forma que priorizem e organizem a assistência laboratorial, para que possam atender em tempo hábil às necessidades da gestante.16

Outras fragilidades detectadas nas falas das gestantes, que são imprescindíveis para o desenvolvimento da assistência pré-natal, foram relacionadas à infraestrutura e ao número insuficiente de profissionais para a realização das consultas:

o aspecto negativo é em relação á estrutura. Eu vejo que tem muitas coisas aqui que não são novas e que já estão degradadas, nos consultórios; a gente ve que os aparelhos não são bons. (GESTA.06)

acho que a estrutura é ponto negativo, não tem assento o suficiente para todas as gestantes e para outras pessoas que precisam de atendimento. Do lado de fora, não tem nenhum tipo de ventilação. (GESTA.14)

o ruim é que não tem ventilador do lado de fora, o calorzão que faz é ruim para gente, é abafado demais. (GESTA.13) 
um aspecto bem ruim é que não tem ventilador aqui aonde a gente espera a consulta. (GESTA.20)

a água é ruim, é estranha a água, o ambiente também é ruim, já que não tem como ter ar condicionado aqui fora porque é aberto, deveria colocar pelo menos ventilador. (GESTA.19)

muita gente para pouca enfermeira. Às vezes, a gente vem no dia e já não tem mais vaga. (GESTA.05)

um ponto negativo é que tem pouco enfermeiro, precisaria de mais enfermeiro e mais médico aqui. (GESTA.18)

Os depoimentos demonstram a escassez de recursos humanos e materiais para que o trabalho na APS seja desenvolvido de forma eficiente. Estes contrariam a Política Nacional de Humanização em que humanizar a assistência consiste em oferecer atendimento de qualidade proporcionando articulação entre os avanços tecnológicos com o acolhimento, com a melhoria dos ambientes de cuidados, com a melhoria das condições de trabalho dos profissionais de saúde e com o quantitativo suficiente de profissionais para atender a demanda nas UBS. Portanto, quando há condições de trabalho insatisfatórias, há também dificuldade para a operacionalização de um cuidado qualificado. ${ }^{19}$

Segundo o MS, para que a assistência pré-natal seja desenvolvida de forma efetiva, os serviços de saúde precisam dispor de área física adequada para atender as gestantes e seus acompanhantes, com condições satisfatórias de higiene e ventilação; equipamentos e instrumentos mínimos para acolhimento, escuta e consulta qualificada como, por exemplo, mesa, cadeiras, mesa ginecológica, fita métrica, SonarDoppler, medicamentos básicos e vacinas. ${ }^{1}$

De acordo com as percepções das gestantes foi possível identificar diversas fragilidades na assistência pré-natal, tais como: a falta de organização dos serviços de saúde, deficiência na 
estrutura física, falta de recursos humanos e materiais. A intervenção das instituições de saúde na resolução das fragilidades detectadas são fatores que contribuem de forma contundente para a melhoria da qualidade da assistência pré-natal na APS.

\section{Considerações finais}

Os depoimentos das gestantes evidenciaram que as potencialidades encontradas na assistência pré-natal no distrito sanitário em estudo foram caracterizadas pelo acolhimento, apoio, escuta ativa, esclarecimento de dúvidas, consulta de enfermagem, o fácil acesso à UBS, acesso aos exames via Rede Cegonha, acesso aos grupos de gestantes, embora este tenha sido limitado a um pequeno número de gestantes.

Com relação às fragilidades na assistência pré-natal, evidenciou-se a falta de organização da APS para a assistência pré-natal, falta de recursos materiais para realização da consulta, de medicamentos essenciais de uso na gravidez e consultório específico de enfermagem; tempo prolongado de espera para início das consultas; demora e a não realização dos exames; infraestrutura insatisfatória e número insuficiente de profissionais.

Percebeu-se que apesar das potencialidades encontradas no serviço de pré-natal oferecido pela APS, as fragilidades sobressaíram-se na percepção das gestantes, que as apontaram mais facilmente. Considerando as potencialidades e as fragilidades na operacionalização do pré-natal, constatou-se que, apesar de a maioria das gestantes estarem satisfeitas com a consulta de pré-natal, os dados revelam muitas limitações em diversos aspectos que concerne aos parâmetros de adequação do pré-natal, preconizados pelo MS.

Como limitação destaca-se as dificuldades na obtenção das participantes pela especificidade da amostra, uma vez que são gestantes de terceiro trimestre. Todavia, apreender as experiências das gestantes a respeito da assistência pré-natal, bem como a importância e entendimento dos cuidados condizentes a esta prática de saúde foi transformador, ampliando a 
compreensão da realidade de como está sendo conduzida a assistência pré-natal. Conclui-se que a avaliação da assistência pré-natal, a partir da percepção das usuárias, é excelente ferramenta para a análise da qualidade dos serviços de saúde direcionados às gestantes. Assim, contribuem para a sensibilização e capacitação dos profissionais envolvidos na gestão e na assistência prénatal e para o desenvolvimento de novas pesquisas relacionadas à implementação das ações e estratégias preconizadas pelo MS, promovendo a melhoria dos serviços de assistência à gestante.

\section{Referências}

1. Brasil. Ministério da Saúde. Secretaria de Atenção à Saúde. Departamento de Atenção Básica. Atenção ao pré-natal de baixo risco. Brasília (DF): Ministério da Saúde; 2012.

2. Mascarenhas PM, Silva GR, Reis TT, Casotti CA, Nery AA. Análise da Mortalidade Materna. Rev Enferm UFPE Online [Internet]. 2017 [acesso em 2017 out 10];11(11):4653-62. Disponível em: https://periodicos.ufpe.br/revistas/revistaenfermagem/article/download/231206/25208.

3. Ferreira ABH. Dicionário da língua portuguesa. 5 ed. Curitiba: Positivo; 2010. 2222p.

4. Brasil. Ministério da Saúde. Portaria n. 569, de 1 de junho de 2000. Institui o Programa de Humanização no Pré-Natal e Nascimento no âmbito do Sistema Único de Saúde [Internet]. 2000 [acesso em 2017 nov 20]. Diário Oficial da União, Brasília (DF); 2000 jun 01. Seção 1, p. 4-6. Disponível em: http://bvsms.saude.gov.br/bvs/saudelegis/gm/2000/prt0569_01_06_2000_rep.html.

5. Brasil. Ministério da Saúde. Secretaria de Atenção à Saúde. Departamento de Ações Programáticas Estratégicas. Pré-natal e puerpério: atenção qualificada e humanizada. Brasília (DF): Ministério da Saúde; 2005.

6. Brasil. Ministério da Saúde. Portaria n. 2.351, de 5 de outubro de 2011. Altera a Portaria no 1.459 , de 24 de junho de 2011, que institui, no âmbito do Sistema Único de Saúde (SUS), a Rede Cegonha [Internet]. 2011 [acesso em 2017 dez 05]. Diário Oficial da União, Brasília (DF); 2011 jul 27. Disponível em: http://bvsms.saude.gov.br/bvs/saudelegis/gm/2011/prt2351_05_10_2011.html.

7. Rosand GB, Slinning K, Roysamb E, Tambs K. Relationship dissatisfaction and other risk factors for future relationship dissolution: a population-based study of 18.523 couples. Soc Psychiatry Psychiatr Epidemiol. 2014;49(1):109-19. 
8.Barreto CN, Ressel LB, Santos CC, Wilhelm LA, Silva SC, Alves CN. Prenatal care in the voice of pregnant women. Rev Enferm UFPE Online [Internet]. 2013 [acesso em 2017 out 10];7(5):4354-63. Disponível em: https://periodicos.ufpe.br/revistas/revistaenfermagem/article/view/11674/13850.

9.Bardin L. Análise de Conteúdo. Lisboa: Edições 70; 2009. 281p.

10. Brasil. Ministério da Saúde. Secretaria de Atenção a Saúde. Departamento de Ações Programáticas Estratégicas. Gravidez, parto e nascimento com saúde, qualidade de vida e bem-estar. Brasília (DF): Ministério da Saúde; 2013.

11. Brasil. Ministério da Saúde. Caderneta da Gestante. 3ª̣ ed. Brasília (DF): Ministério da Saúde; 2016.

12. Brasil. Ministério da Saúde. Resolução 466, de 12 de dezembro de 2012. Aprova as diretrizes e normas regulamentadoras de pesquisas envolvendo seres humanos [Internet]. $2012 \mathrm{dez} 12 \mathrm{dez}$ [acesso em 2017 out 10]. Disponível em: http://bvsms.saude.gov.br/bvs/saudelegis/cns/2013/res0466_12_12_2012.html.

13. Alkema L, Chou D, Hogan D, Zhang S, Moller AB, Gemmill A, et al. Global, regional, and national levels and trends in maternal mortality between 1990 and 2015, with scenario-based projections to 2030: a systematic analysis by the UN Maternal Mortality Estimation Inter-Agency Group. Lancet. 2016;387(10017):462-74.

14. Santos JO, Pacheco TS, Oliveira PS, Pinto VL, Gabriellone MC, Barbieri M. The obstetrical and newborn profile of postpartum women in maternities in São Paulo. Rev Pesqui Cuid Fundam [Internet]. 2015 jan [acesso em 2017 out 10];7(1):1936-45. Disponível em: http://www.seer.unirio.br/index.php/cuidadofundamental/article/view/3547/pdf_1432.

15. Santiago CMC, Sousa CNS, Nóbrega LLR, Salees L, Morais F. Assistência pré-natal e as práticas desenvolvidas pela equipe de saúde: revisão integrativa. Rev Pesqui Cuid Fundam [Internet]. 2017 jan [acesso em 2017 out 29];9(1):279-88. Disponível em: http://www.seer.unirio.br/index.php/cuidadofundamental/article/view/4184/pdf_1.

16. Castro ECM, Leite AJM, Guinsburg R. Mortalidade com 24 horas de vida de recém-nascidos prétermo de muito baixo peso da Região Nordeste do Brasil. Rev Paul Pediatr. 2016;34(1):106-13.

17. Oliveira JCS, Fermino BPD, Conceição EPM, Navarro JP. Assistência pré-natal realizada por enfermeiros: o olhar da puérpera. Rev Enferm Cent-Oeste Min. 2015 maio-ago;5(2):1613-28.

18.Campos ML, Veleda AA, Coelho DF, Telo SV. Percepção das gestantes sobre as consultas de pré-natal realizadas pelo enfermeiro na atenção básica. J Nurs Health. 2016;6(3):379-90.

19. Feliciano NB, Pradebon VM, Lima SS. Enfermagem no pré-natal de baixo risco na estratégia Saúde da Família. Aquichan. 2013;13(2):261-9. 


\section{Autor correspondente}

Andressa Arraes Silva

E-mail: andressinha_arraes5@hotmail.com

Endereço: Avenida 01, quadra 30, casa 09, COHAB 2

CEP: 65700000

\section{Contribuições de Autoria}

1 - Andressa Arraes Silva

Autora principal, participou desde o planejamento da pesquisa até a elaboração do produto submetido em forma de artigo.

1 - Mara Julyete Arraes Jardim

Contribuiu na análise e organização dos dados para disposição das informações finais do artigo.

2 - Claudia Teresa Frias Rios

Contribuiu na análise e interpretação dos dados, redação e revisão crítica do artigo.

3 - Lena Maria Barros Fonseca

Orientadora, participou desde o planejamento da pesquisa até a elaboração do artigo submetido.

4 - Liberata Campos Coimbra

Contribuiu na análise e interpretação dos dados, redação e revisão crítica do artigo.

\section{Como citar este artigo}

Silva AA, Jardim MJA, Claudia Rios TF, Fonseca LMB, Coimbra LC. Pré-natal da gestante de risco habitual: potencialidades e fragilidades. Rev. Enferm. UFSM. 2019 [Acesso em: 2019 jun 15];vol ex:p1-20. DOI:https://doi.org/10.5902/2179769232336 